SHORT REPORT

\title{
Decreasing prevalence of obesity in primary schoolchildren
}

\author{
Rod Thomas Mitchell, Catherine M McDougall, Jacqueline E Crum
}

Arch Dis Child 2007;92:153-154. doi: 10.1136/adc.2006.102731

The prevalence of obesity in a cohort of Scottish primary schoolchildren was assessed and compared with previous cohorts taken from the same geographical area. The prevalence of obesity has declined over the three time periods studied, from $14.7 \%$ to $10.2 \%$. Body mass index (BMI) centiles and BMI standard deviation scores have also declined considerably over time.

O besity has been widely described as the latest epidemic. There is increasing awareness of both the immediate and long-term adverse outcomes of obesity in terms of both physical and psychological effects. Evidence suggests that obesity is increasing in many countries, including the UK. ${ }^{1}$ We previously conducted a study on the prevalence of overweight and obesity in primary school children in Aberdeen, which showed a reduction in the prevalence of overweight between 1997 and 2001 . $^{2}$ We designed a follow-up study to investigate whether this unexpected trend had persisted in a subsequent cohort.

\section{METHODS}

The data were collected from the school nurse records for children who were in primary year one in 2004. All school nurses had received regular standardised training for measuring and weighing children. All the children were pupils from one of 17 city primary schools in Aberdeen. These schools were the same schools that were studied previously. ${ }^{2}$ Height (to $0.1 \mathrm{~cm}$ with a portable stadiometer, Raven Minimetre (Raven Equipment, Essex, UK) and weight (to $0.1 \mathrm{~kg}$ with Seca scales (Seca Scales, Brooklyn, USA), in light indoor clothing) were taken for all children as part of their primary year one medical examination. Body mass index (BMI) was calculated (weight $(\mathrm{kg}) /$ height $\left.^{2}\left(\mathrm{~m}^{2}\right)\right)$, and data converted to BMI centiles and standard deviation (SD) scores using the UK 1990 reference data for BMI in childhood. ${ }^{3}$ Overweight was defined as BMI $\geqslant 85$ th centile $(\mathrm{SD} \geqslant 1.04$ ) and obesity as $\mathrm{BMI} \geqslant 95$ th centile $(S D \geqslant 1.64)$, as in our previous study.

\section{Statistical analysis}

A comparison was made with the primary year 1 cohorts from 1997 and 2001. The percentages of overweight and obese children in the three cohorts were compared by a $\chi^{2}$ test. Mean (SD) BMI scores were compared using unpaired t test. The BMI centile values were not normally distributed and so the MannWhitney $U$ test was used to compare the primary year one cohorts.

\section{RESULTS}

Data were collected from 334 primary year 1 children in 2004, which included every child who had received a primary year 1 medical examination for each of the schools studied. There were 178 boys and 156 girls, with an average age of 5.66 years. The sex and age distributions were comparable with the previous primary year 1 cohorts. There is a clear downward trend in the prevalence of obesity over the period studied. In 1997 , the prevalence of obesity was $14.7 \%$, decreasing to $11.4 \%$ in 2001. The figure for 2004 has decreased even further to $10.2 \%$. This trend was present in boys and girls when assessed separately (fig 1).

The prevalence of overweight in 2004 was $24 \%$. This is lower than the 1997 cohort but an increase over the figures for 2001. There was no significant difference in the prevalence of overweight in 2004 when compared with the previous figures of 1997 and 2001. A higher proportion of boys than girls were overweight in each year studied. The mean (SD) BMI score for 2004 was 0.18 . This had decreased further than the mean (SD) BMI score for 2001 of 0.35 , and remained significantly lower compared with that for 1997 (BMI SD score $=0.49, \mathrm{p}<0.001$ ). This finding was consistent in both boys $(\mathrm{p}=0.006)$ and girls $(p=0.003)$. The median BMI centile in 2004 remained lower than in $1997(\mathrm{z}=3.85, \mathrm{p}=0.000)$ and was again consistent in both boys $(z=2.66, p=0.008)$ and girls $(z=2.92, p=0.003)$.

\section{DISCUSSION}

This study showed that the prevalence of obesity in Aberdeen children entering primary education has been declining between 1997 and 2004. This is in stark contrast to previously published data, which have shown that obesity has increased in UK children in recent years. ${ }^{1}$ The overall prevalence of obesity in our study $(10.2 \%)$ is comparable with that obtained in earlier studies. This includes a study of 2630 English children in 1999, which reported a prevalence of obesity of $10.4 \%{ }^{4}$ There has been no significant change in the prevalence of overweight between the three cohorts studied, despite the trend in obesity. We have also showed a considerable and sustained decrease in median BMI centiles in these children, which is opposed to data previously published and reviewed by the Scottish Intercollegiate Guidelines Network. ${ }^{5}$

We acknowledge that a potential confounding factor for these results would include changes in the socioeconomic structure over the time period studied. We therefore assessed

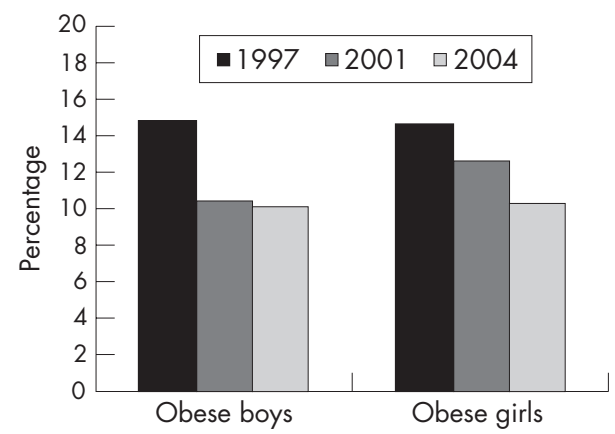

Figure 1 Prevalence of obesity in boys and girls for each of the 3 years studied.

Abbreviations: BMI, body mass index; DEPCAT, deprivation category 
deprivation on the basis of the postal codes for the areas studied and found no significant difference in either Carstairs or deprivation category (DEPCAT) scores using the census data for $1991^{6}$ compared with that for 2001. ${ }^{7}$ Our study included children from areas with DEPCAT scores ranging from 1 to 6 , with an average DEPCAT score of between 3 and 4 , which represents the middle range for this measure of deprivation.

It is important to attempt to identify factors that may account for these trends. It should also be remembered that the eating and activity behaviours of primary year 1 school children are largely under the influence of their parents. Awareness of the problem of obesity in the adult population has increased substantially in the past few years, and many public health initiatives have been launched to encourage healthy eating and regular exercise. It is possible that these are beginning to have some effect. Scottish Intercollegiate Guidelines Network guidelines on the management of obesity in children and young people were published in April 2003, with recommendations for the prevention and treatment of obesity, ${ }^{5}$ and this may contribute further to the overall awareness of obesity. As the guidelines are relatively recent, they probably have not affected the results of our study.

Despite these results, obesity remains an important cause of morbidity and mortality, and effective treatment remains a difficult proposition. The prevalence of obesity is still twice as high in our study as was predicted from the UK 1990 reference data for BMI in childhood. ${ }^{3}$ We must continue to monitor trends in overweight and obesity to assess the effectiveness of any intervention and also to identify whether these trends persist into the older children once they have more control over their eating and exercise habits. The results of this study have been in contrast with previous reports on obesity and may provide some optimism for the future.

\section{ACKNOWLEDGEMENTS}

We thank the school nurses who undertook the routine child health surveillance and carried out the height and weight measurements.

\section{Authors' affiliations}

Rod Thomas Mitchell, Jacqueline E Crum, Department of Community Child Health, Royal Aberdeen Children's Hospital, Aberdeen, UK

Catherine M McDougall, Department of Child Health, University of Aberdeen, Royal Aberdeen Children's Hospital, Aberdeen, UK

Competing interests: None.

Correspondence to: Dr R T Mitchell, Department of Community Child Health, Royal Aberdeen Children's Hospital, Westburn Road, Aberdeen AB25 2ZG, UK; r.mitchell@hrsu.mrc.ac.uk

Accepted 29 October 2006

Published Online First 6 November 2006

\section{REFERENCES}

1 Stamatakis E, Primatesta P, Chinn S, et al. Overweight and obesity trends from 1974 to 2003 in English children: what is the role of socioeconomic factors? Arch Dis Child 2005;90:999-1004.

2 McDougall CM, Crum JE. Changing prevalences of overweight and obesity in primary schoolchildren: a glimmer of hope? Scott Med J 2006:51:34-6.

3 Cole TJ, Freeman JV, Preece MA. Body mass index reference curves for the UK 1990. Arch Dis Child 1995;73:25-9.

4 Reilly JJ, Dorosty AR. Epidemic of obesity in UK children [letter]. Lancet 1999:354:1874-5.

5 Scottish Intercollegiate Guidelines Network (SIGN). Management of obesity in children and young people, SIGN publication number 69. Edinburgh: SIGN, 2003.

6 McLoone P. Carstairs scores for Scottish postcode sectors from the 1991 census. http://www.isdscotland.org/isd/files/postcode_1991_Carstairs.zip.

7 McLoone P. Carstairs scores for Scottish postcode sectors from the 2001 census. http://www.isdscotland.org/isd/files/postcode_2001_Carstairs.zip.

\section{International Forum on Quality \& Safety in Health Care}

18-20 April 2007

Palau de Congressos, Barcelona

\section{Registration now open}

- Book by 23 February 2007 and save up to $£ 60$ on the 3-day delegate fee

- Join us at the premier international event for those dedicated to improving quality and safety in health care

- Speakers include: Donald Berwick, Sir John Oldham, Lucien Leape, Richard Smith, Helen Bevan, Lloyd Provost and Rosa Sunol

- For more information and to book online please visit: www.quality.bmipg.com 